\title{
Resiliência e relações públicas: diálogos e reflexões
}

Resilience and public relations: dialogues and reflections

Resiliencia y relaciones públicas: diálogos y reflexiones

Roberto José Ramos

- PhD em Ciências da Comunicação pela Universidade do Vale do Rio dos Sinos (Unisinos) Doutor em Educação pela Pontifícia Universidade Católica do Rio Grande do Sul (PUC-RS)

- Mestre em Linguística e Letras pela PUC-RS

- Graduado em Comunicação Social - Jornalismo pela PUC-RS

- Professor dos cursos de graduação e pós-graduação da Faculdade dos Meios de Comunicação Social da PUC-RS)

- Obras publicadas: Futebol: ideologia do poder; Grã-finos na Globo; Manipulação e controle da opinião pública; A máquina capitalista: mídia, textos e contextos (Org.); A ideologia da Escolinha do Professor Raimundo; e Os sensacionalismos do sensacionalismo: uma leitura dos discursos midiáticos

- E-mail:rr@pucrs.br

\section{Fernanda Lopes de Freitas}

- Doutoranda em Comunicação Social no Programa de Pós-Graduação em Comunicação da Pontifícia Universidade Católica do Rio Grande do Sul (PUC-RS)

- Mestre em Comunicação Social pela PUC-RS

- Bacharel em Comunicação Social - Relações Públicas pela PUC-RS

- E-mail: fernanda.freitas.001@acad.pucrs.br 


\section{Resumo}

0 conceito de resiliência assumiu uma característica transdisciplinar. Está presente em diversas áreas do conhecimento, onde até então nem sequer o percebíamos, permeando, inclusive, a vida organizacional e suas diversas interfaces. Sendo assim, como pode dialogar e trazer contribuições, para relações públicas? Tal questão conduzirá as reflexões do presente artigo.

PALAVRAS-CHAVE: RESILIÊNCIA • RELAÇÕES PÚBLICAS• ORGANIZAÇÕES.

\section{Abstract}

The concept of resilience has gained a transdisciplinary aspect. It is present in different areas of knowledge, even where we have not noticed hitherto, permeating corporate routine and its various interfaces. Therefore, how can we discuss and contribute to public relations? Such issue will guide the reflections in this article.

\section{KEYWORDS: RESILIENCE・PUBLIC RELATIONS・ORGANIZATIONS.}

\section{Resumen}

El concepto de resiliencia asumió una característica transdisciplinaria. Está presente en diversas áreas del conocimiento, donde hasta entonces ni siquiera lo percibíamos, atravesando, inclusive, la vida organizacional y sus diversas interfaces. Siendo así, ¿cómo puede dialogar y traer contribuciones, para relaciones públicas? Tal cuestión conducirá las reflexiones del presente artículo. 
resgate etimológico de qualquer palavra é sempre um ato revelador. Traduz significados. Amplia concepções. Parece ser um degrau inicial e, ao mesmo tempo, essencial, quando procuramos produzir o conhecimento, com apego e com rigor científicos.

Assim sendo, a palavra resiliência - às vezes grafada como resilência - precisa ser examinada etimologicamente. Pode assumir uma polissemia. Significa "resistência" e "flexibilidade". Ambas parecem, na generalidade, instituir e constituir a essência da sua abrangência conceitual.

Izabella Moreira de Lucena (2010, p. 17) observa o desenvolvimento dos estudos sobre resiliência em vários países:

Pesquisas sobre resiliência têm sido desenvolvidas na Inglaterra, nos Estados Unidos e no Canadá há cerca de vinte anos, de forma mais especulativa, e, mais especificamente, há quinze anos. Esses estudos, na maioria das vezes, voltam-se, para 0 desenvolvimento emocional de crianças e adolescentes em condições de adversidade ou risco. Nos países andinos, em Portugal e no Brasil, nessa linha de abordagem, as investigações não datam de mais de dez anos.

A Sociedade Brasileira de Resiliência (Sobrare) esclarece sobre o conceito:

O significado da resiliência no ser humano pode ser dito como a capacidade ou habilidade desenvolvida a partir de crenças básicas que estruturam o comportamento das pessoas para a superação. Os resilientes enfrentam situações adversas e de estresse elevado com habilidade de enxergar, compreender e tomar decisões apropriadas para superar e vencer as adversidades nas diferentes áreas da vida (2012, p. 1).

$\mathrm{Na}$ contemporaneidade, o conceito tem adquirido um sentido amplo, de características transdisciplinares. Vem circulando em diversos territórios do saber, com unidade e diversidade. Parecem ser os casos que acontecem na física, na psicologia e na administração.

A sua origem se encontra associada aos estudos da física. Foi desenvolvida a partir do século XIX, mais especificamente em 1807, com um dos pioneiros, o cientista inglês Thomas Young. Ele se preocupou com as resistências dos metais, sobretudo, quando submetidos a pressão e, depois, retomando a sua configuração original. Posteriormente, se generalizou, abrangendo diversos objetos. A questão essencial estava localizada na capacidade de resistência. Qualquer pressão pode alterá-los; quando esta cessa, existe a possibilidade de que eles possam recuperar os seus respectivos formatos.

Na psicologia, é a capacidade do indivíduo de lidar com os seus problemas, ultrapassando os obstáculos. Assim sendo, resiliente é aquele que se recupera e se molda a cada deformação/obstáculo situacional. 0 equilíbrio humano se assemelha à estrutura de um prédio. Se a pressão for superior à resistência, aparecerão as rachadoras - as lesões e as doenças, por exemplo. Caso contrário, se conseguirmos enfrentar e superar as adversidades, ocorre um feedback positivo. É 0 fortalecimento da autoestima, com a consequente ampliação da consciência. Em termos psicológicos, a resiliência não é somente um conceito, comprometido com um determinado conhecimento. Significa bem mais. Transcende o conhecer. Associa-o, objetiva e subjetivamente, ao mais verdadeiro, puro e pleno conhecimento: 0 autoconhecimento, com as suas práticas transformadoras.

Na administração, a resiliência faz parte dos processos, que envolvem mudanças e transformações, por vezes, muito rápidas. Para quem trabalha nas organizações, há a necessidade de um grande equilíbrio emocional. Isso é vital, para enfrentar as adversidades e inovações. 
A partir da década de 1970, satélites, celular, interneteas novas tecnologias globalizam o circuito de informação. Materializouse a III Revolução Industrial. Houve as alterações nas dimensões de tempo e de espaço. A geografia foi reduzida. Ao toque de uma tecla, podemos ir a vários lugares, sem sair do mesmo lugar. 0 sociólogo Michel Maffesoli (1988) caracteriza o período contemporâneo como a pós-modernidade, resultante das interações entre o arcaico e as transformações tecnológicas. Essa era possui algumas características básicas: presenteísmo: domínio do presente; tribalismo: cultura do estar-junto; e o barroco: estilo que cultua o conflito e a assimetria.

0 ritmo do tempo, parece ter se alterado sensivelmente. Habitamos e transitamos entre o real e 0 virtual, como rituais, próprios das relações sociais e culturais do cotidiano. Aumentam os desafios. Intensificam-se as reivindicações de que sejamos, cada vez mais, resilientes.

Daryl Conner (1995) apresenta cinco características da resiliência: positividade: ver a vida, como desafiadora, mas cheia de oportunidades; flexibilidade: ser maleável às incertezas; foco: visão clara do que alcançar; organização: gerenciar as ambiguidades; e pró-ação: induz mudanças, ao invés de evitá-las.

Dentro deste contexto pós-moderno, as práticas da atividade de relações públicas convivem com novas solicitações. São exigidas nas pronúncias de diferentes linguagens nas interações entre as organizações e os seus respectivos públicos. Como a resiliência poderá dialogar e contribuir com isso?

\section{A RESILIÊNCIA NAS RELAÇÕES PÚBLICAS}

Buscar compreender e posteriormente explicar o diálogo entre as práticas e os conceitos de relações públicas e resiliência configuram-se como objetivo principal deste artigo, porém só é possível se tivermos uma boa pesquisa bibliográfica que possa levantar considerações sobre este estudo. Por isso, a importância do resgate teórico para entender como o comportamento resiliente pode influenciar o exercício dessa área.

Quando falamos em relações-públicas, logo nos vem à mente seu objeto principal: as organizações como espaço de trabalho e mediação entre os sujeitos. Os públicos são sempre o alvo das ações e práticas desses profissionais, permeando todos os projetos que dizem respeito a essas instituições. Roberto Porto Simões (2001, p. 13-52) conceitua as relações públicas como "gestão da função organizacional política", visando "à ação favorável dos públicos à missão da organização".

Com isso, e para isso, faz-se necessário compreender o comportamento e, sobretudo, as subjetividades que perpassam os sujeitos organizacionais, sendo que estes serão o reflexo da organização e, ao mesmo tempo, refletidos por ela. Assim, o aspecto cultural deve ser evidenciado nos estudos que permeiam esses espaços, já que são fatores determinantes de desempenho, relacionado não somente à produtividade, mas, também, ao processo comunicacional das empresas e demais instituições.

Cabe-nos observar que os públicos, por meio de suas subjetividades, compõem amplos mosaicos multiculturais e influenciam diretamente no comportamento e no clima organizacional. Não obstante, muitas crises são ocasionadas pelos discursos "mal ditos" ou "não ditos" das corporações, o que faz com que se desmotive o bom entendimento nesses ambientes. Para Edgar Morin (2006, p. 91), "as relações no interior de uma organização, de uma sociedade, de uma empresa são complementares e antagônicas ao mesmo tempo". 
0 mercado em que as organizações estão inseridas - seu macroambiente - representa um fator importante, que se faz perceber na sua cotidianidade, bem como na tomada de decisões das organizações. Inegavelmente, a sociedade está passando por transformações cada vez maiores e que interferem proporcionalmente no dia a dia organizacional, como, por exemplo, a questão tecnológica, que, mesmo que quase imperceptivelmente, faz parte da nossa rotina.

Essas mudanças, contudo, podem ser sentidas no relacionamento entre o sistema organização-públicos, uma vez que ambos têm de se adaptar a novas realidades e exigências sociais, políticas, econômicas e - por que não dizermos? tecnológicas também. Os processos de adaptação a essas novas perspectivas nem sempre conseguem ser acompanhadas pelas organizações, o que as leva a se tornarem obsoletas, perdendo, assim, seu espaço no mercado. Nesse contexto, cabe-nos compreender como a resiliência é um fator que pode ser percebido no processo de relações públicas, já que ela deve ser uma característica indispensável para organizações aspirantes a um futuro de sucesso.

Morin (2006, p. 89) evidencia que as organizações tendem a se integrar e desintegrar, o que nos remete à resiliência. 0 autor pormenoriza:

Toda organização, como fenômeno físico, organizacional e, claro, vivo tende a se degradar e a degenerar. 0 fenômeno da desintegração e da decadência é um fenômeno normal. Ou seja, normal não é que as coisas permaneçam tais como são, quais pelo contrário seria inquietante (sic). Não há uma receita de equilíbrio. A única maneira de lutar contra a degenerescência está na regeneração permanente, melhor dizendo, na atitude do conjunto da organização a se regenerar e a se reorganizar fazendo frente aos processos de desintegração.

Como já mencionado, anteriormente, a resiliência é a capacidade de transformar-se ou adaptar-se a determinadas situações adversas, conseguindo voltar ao estágio normal. Esse conceito, assim como outros tantos utilizados na gestão das empresas vem da física, da engenharia, da industrialização dos produtos - visto que, na sociedade em que estamos inseridos, o forte apelo a relacionamentos e subjetividades em série tornam-se vitais para que sejamos resilientes.

Não devemos nos esquecer de que as organizações são espaços onde as culturas são múltiplas e interferem diretamente no seu funcionamento. 0 trabalho de relações públicas é mediar os interesses diversos dos públicos, bem como fortalecer o aspecto cultural da organização, promovendo, assim, uma imagem positiva. Para Edgar Schein (1985, p. 9), a cultura organizacional pode ser definida como

o conjunto de pressupostos básicos que um grupo inventou, descobriu ou desenvolveu ao aprender como lidar com os problemas de adaptação externa e integração interna e que funcionaram bem o suficiente para serem considerados válidos e ensinados a novos membros como a forma correta de perceber, pensar e sentir, em relação a estes problemas.

Para tanto, se faz necessário que as relações públicas, dentro de suas dinâmicas e práticas, não somente desenvolvam espaços de trocas de poder, de interesses, culturas e subjetividades em geral, mas, sim, desenvolvam sujeitos e posturas resilientes nesses ambientes.

De acordo com alguns autores, as organizações são ambientes transferenciais, pois, além de induzirem seus públicos a aderirem aos seus aspectos culturais e rituais, também acabam por incorporar esses mesmos fatores de seus públicos, como podemos compreender por meio de Maria Ester Freitas (2000, p. 89-90):

Neste sentido, pode-se dizer que a organização/empresa é um lugar de transferência espontânea, mas também induzida, embora na maioria das vezes seja transferência apenas daquilo que pode ser traduzido em afetos, emoções, qualidades, atitudes e comportamentos adaptados e canalizados para seus objetivos. Estimulam-se não só as relações de obediência, lealdade e devoção, mas também as demonstrações narcísicas, agressivas e idealizadoras, tendo ambas sua utilidade produtiva. 
Parece-nos imprescindível compreender que as organizações são espaços onde sujeitos representam papéis, como também é por meio de seus comportamentos e seus aportes subjetivos que conseguimos trabalhar os processos comunicacionais. A comunicação necessita desses aspectos para se desenvolver dentro de cada segmento, se fazendo entender, mesmo por meio dos inúmeros conflitos e crises pelas quais as instituições passam.

Levado por muitas transformações, dos mais diversos tipos, o macroambiente muda velozmente. Os públicos possuem noções temporais diferentes e, muitas vezes, não condizentes com as mudanças propostas. Por isso, além das questões culturais das organizações, devemos, também, perceber o clima organizacional, como refletor da sociedade em geral.

É uma nova economia que está se instaurando, repaginando não somente questões financeiras, mas também aspectos sociais, conforme diz Manuel Castells (2007, p. 87):

Uma nova economia surgiu em escala global nas duas últimas décadas. Chamo-a de informacional e global para identificar suas características fundamentais e diferenciadas e enfatizar sua interligação. É informacional porque a produtividade e a competitividade de unidades ou agentes nessa economia (sejam empresas, regiões ou nações) dependem basicamente de sua capacidade de gerenciar, processar e aplicar de forma eficiente a informação baseada em conhecimentos. É global porque as principais atividades produtivas, o consumo e a circulação, assim como seus componentes (capital, trabalho, matéria-prima, administração, informação, tecnologias e mercados) estão organizados em escala global, diretamente ou mediante uma rede de conexões entre agentes econômicos.

Castells, assim, deixa evidente que as transformações em curso vão além dos "muros" das empresas, perpassam nossa vida em todos os setores, estão além do que podemos controlar. Esse fator também está ligado a emocionalidade dos sujeitos, é uma característica indissociável do indivíduo como um todo, sendo, assim, influenciador nos processos das corporações.

A nova economia, como nos propõe Castells, tem seu foco no relacionamento interpessoal, mediado pelas novas tecnologias da comunicação (talvez nem tão novas assim). Outro ponto que também é central é a mudança da sociedade, hoje informacional ou em rede, como o mesmo autor diz, caracterizada por uma corrida cada vez mais veloz para acompanhar as informações que perpassam nosso cotidiano full time.

Para as organizações acompanharem essas mudanças no nível do macroambiente, faz-se primordial desempenhar uma comunicação e um comportamento internos alinhados às novas exigências sociais, políticas e econômicas. Castells chama essa nova ordem social de economia da velocidade, justamente por se tratar de mudanças bruscas afetando proporcionalmente e diretamente a vida dos públicos e seu desempenho as organizações.

Hoje, temos consumidores mais exigentes e com acesso crescente a informações no que tange aos produtos de uma determinada marca, bem como dos concorrentes. Há uma grande segmentação dos públicos internos e externos às organizações, o que exige relacionamentos bem geridos, proporcionando comunicação e comportamentos lineares.

Além de processos comunicacionais, temos as relações de poder emergindo em organizações cada vez mais globalizadas e provocando a exclusão de mercado de empresas que não possuem know-how ou, ainda, capacidade resiliente para enfrentar a nova realidade socioeconômica vigente.

A inovação e as relações em rede são a nova ordem social, pois a produtividade atrelada à economia informacional exige uma laboriosidade maior e de alta qualidade. Temos consumidores mais exigentes e com amplo conhecimento sobre 0 que estão consumindo, sendo a empresa alvo de observação apurada por parte dos stakeholders. Castells (2002, p. 35) corrobora essa ideia: 


\begin{abstract}
No nível da estrutura corporativa, as empresas informacionais aumentam a produtividade, benefícios e valor de cotação organizando-se (globalmente) como redes, aplicando tecnologia informacional e centrando-se crescentemente na manutenção de informação (símbolos). Isto se aplica à relação da companhia com seus empregados, seus clientes e os mercados financeiros. No que diz respeito aos funcionários, à gestão, à inovação e produção se organizam como redes globais que se podem coordenar com ajuda de redes informáticas.
\end{abstract}

Portanto, a partir dessas novas exigências, tona-se necessário que as empresas sejam resilientes para que possam permanecer no mercado. Como já mencionado anteriormente (Morin, 2002), as organizações precisam se degenerar e se regenerar, continuamente, fato este que pode ser observado na contemporaneidade, por meio da economia da velocidade ou, como podemos deduzir, sociedade da velocidade, na qual as ações e reações acontecem num curto espaço de tempo e os públicos acabam por perder tanto a noção espacial quanto a temporal, modificando, assim, a lógica das suas relações.

Essas organizações-rede, como Castells as conceitua, são multiculturais e globais. Por isso, carregam em seu cerne as diferenças individuais dos sujeitos, suas emocionalidade e potencialidades, sendo um fator agregador e antagônico, simultaneamente, para uma empresa mais genérica. Ao mesmo tempo, a partir dessas divergências de interesses e personalidades, abrem-se espaços propícios a conflitos e crises, dando a matiz da contemporaneidade ou, como diz Maffesoli, da pós-modernidade, a partir de uma composição híbrida.

As relações púbicas, frente a essa nova realidade, precisam ser resilientes, visto que a busca por novos aportes teóricos e práticos se investe de grande relevância, aspirando mediar os interesses do sistema organizações-públicos a partir desse cenário eminente. No entanto, a promoção de comportamentos resilientes também é uma tarefa dessa área, já que está intimamente ligada à comunicação e ao relacionamento entre os sujeitos.

Conner (1995) enumera as cinco características da resiliência que se encaixam, no momento atual e permeiam as organizações, onde proatividade e flexibilidade são pontos essenciais. Estes dois fatores, no contexto em que estão inseridos, se fazem primordiais, considerando-se que as empresas necessitam ser proativas, diante de seus stakeholders, bem como flexíveis, diante dos diversos fatores, tanto do micro quanto do macroambiente, na busca do sucesso e de sua manutenção forte e estável no mercado.

\title{
CONSIDERAÇÕES FINAIS
}

A sociedade está mudando aceleradamente e as organizações - produtos e produtores da mesma - também estão se transformando. As novas tecnologias, a perda de noção de espaço e tempo, as relações permeadas pela individualidade e, ao mesmo tempo, expostas e interativas com o coletivo, entre tantas outras evidências, parecem marcar a pós-modernidade e, destacadamente, nossa vida.

Nos ambientes organizacionais encontramos o reflexo deste momento, em que as relações de poder se tornaram, progressivamente, mais acirradas, tanto em seus espaços internos, quanto externos. A concorrência tornou-se algo quase desleal, visto que produtos e serviços são oferecidos com os mesmos atributos, para segmentos idênticos.

Ao longo deste trabalho constatamos que as relações públicas, diante deste novo contexto social, político e econômico, dialoga, diretamente e visceralmente, com a resiliência. As organizações pós-modernas trazem uma necessidade urgente de estimular e/ou transformar seus processos comunicacionais, bem como seus relacionamentos, tendo na resiliência um objetivo concreto, frente às intempéries mercadológicas e às demais transformações predominantes neste novo contexto organizacional. 


\section{REFERÊNCIAS}

CASTELLS, Manuel. A sociedade em rede. São Paulo: Paz e terra, 2007.

O Estado do bem estar e a sociedade da informação: o modelo finlandês. Madrid: Alianza Editorial, 2002.

CONNER, Daryl. Gerenciando na velocidade da mudança. Rio de Janeiro: Infobook, 1995.

FREITAS, Maria Ester. Cultura organizacional: identidade, sedução e carisma? Rio de Janeiro: FGV, 2000.

LUCENA, Izabella Moreira de. Resiliência, judaísmo e cultura organizacional: inter-relações e reflexos. Recife: Editora do Autor, 2010.

MAFFESOLI, Michel. Apocalipse: opinião pública e opinião publicada. Porto Alegre: Sulina, 2010.

O conhecimento comum: compêndio de sociologia compreensiva. São Paulo: Brasiliense, 1988.

MORIN, Edgar. Introdução ao pensamento complexo. Porto Alegre: Sulina, 2006.

Terra-pátria. Porto Alegre: Sulina, 2002.

SCHEIN, Edgar H. Cultura organizacional e liderança. São Francisco, CA: Jossey-Bass Inc. Publishers, 1985.

SIMÕES, Roberto Porto. Relações públicas e micropolítica. São Paulo: Summus, 2001.

SOBRARE. Resiliência no contexto atual. Disponível em: <http://www.sobrare.com.br>. Acesso em: 16 nov. 2012.

Artigo recebido em 19.06.2013 e aprovado em 21.12.2013. 